\title{
Tissue Window in Stroke Thrombolysis Study (TWIST): A Safety Study
}

\author{
Michael D. Hill, Carol Kenney, Imanuel Dzialowski, Jean-Martin Boulanger, \\ Andrew M. Demchuk, Philip A. Barber, Timothy W.J. Watson, Nicolas U. Weir, \\ Alastair M. Buchan for the Calgary Stroke Program
}

\begin{abstract}
Background: Stroke thrombolysis is limited by the "last-seen well" principle, which defines stroke onset time. A significant minority of stroke patients $(\sim 15 \%)$ awake with their symptoms and are by definition ineligible for thrombolysis because they were "last-seen well" at the time they went to bed implying an interval that is most often greater than three hours. Methods: A singlecentre prospective, safety study was designed to thrombolyse 20 subjects with stroke-on-awakening. Patients were eligible for inclusion if they were last seen well less than 12 hours previously, specifically including those who awoke from sleep with their stroke deficits. They had a baseline computed tomogram (CT) scan with an ASPECTS score greater than 5, no evidence of well-evolved infarction and a CT angiogram / Trans-cranial Doppler ultrasound study demonstrating an intracranial arterial occlusion. Patients fulfilled all other standard criteria for stroke thrombolysis. The primary outcome was safety defined by symptomatic ICH or death. Results: Among 89 screened patients, 20 were treated with thrombolysis. Two patients $(10 \%)$ died due to massive carotid territory stroke and two patients $(10 \%)$ died of stroke complications. Two patients (10\%) showed asymptomatic intracerebral hemorrhage (ICH) (petechial hemorrhage) and none symptomatic ICH. Reasons for exclusion were: (a) ASPECTS $\leq 5$ (29); (b) well-evolved infarcts on CT (19); (c) historical mRS > 2 (17); (d) no demonstrable arterial occlusion or were too mild to warrant treatment (10). Conclusions: Patients who awake with their deficits can be safely treated with thrombolysis based upon a tissue window defined by NCCT and CTA/TCD.
\end{abstract}

RÉSUMÉ: Tissue Window in Stroke Thrombolysis Study (TWIST) : une étude d'innocuité. Contexte : La thrombolyse dans l'accident vasculaire cérébral (AVC) est limitée par le « last-seen well principle » c'est-à-dire le moment où le patient a été vu pour le dernière fois en santé, qui définit le moment du début de l'AVC. Une importante minorité de patients atteints d'un AVC, soit environ 15\% de ces patients, se réveille alors que leurs symptômes sont déjà présents et sont par définition inéligibles à la thrombolyse parce qu'ils ont été vus en bonne santé pour la dernière fois au moment où ils se sont couchés, ce qui implique un intervalle qui est le plus souvent supérieur à trois heures. Méthode : Nous avons conçu une étude prospective d'innocuité effectuée dans un seul centre pour traiter par thrombolyse 20 patients présentant un AVC à leur réveil. Les patients étaient éligibles à l'étude s'ils avaient été vus en bonne santé moins de 12 heures auparavant, incluant spécifiquement ceux qui se sont réveillés avec leurs déficits dus à un AVC. À la tomodensitométrie de référence, ils avaient un score ASPECTS plus grand que 5, pas d'évidence d'infarctus bien établi et une angiographie par tomodensitométrie/une échographie Doppler transcrânienne démontrant une occlusion artérielle intracrânienne. Les patients rencontraient tous les autres critères standards pour le traitement par thrombolyse d'un AVC. L'issue principale pour évaluer la sécurité était l'hémorragie intracrânienne (HIC) symptomatique ou le décès. Résultats : Vingt des 89 patients dépistés ont subi une thrombolyse. Deux patients sont décédés (10\%) à cause d'un AVC massif dans le territoire de la carotide et deux patients (10\%) sont décédés des complications de l'AVC. Deux patients (10\%) ont présenté une HIC asymptomatique (hémorragie pétéchiale) et aucun patient n'a présenté une HIC symptomatique. Les motifs d'exclusion étaient les suivants : a) un score ASPECTS $\leq 5$ chez 29 patients; b) un infarctus bien établi à la tomodensitométrie chez 19 patients; c) un score de Rankin modifié $>2$ chez 17 patients; d) pas d'occlusion artérielle objectivée ou trop discrète pour justifier un traitement chez 10 patients. Conclusions : Les patients qui présentent des déficits neurologiques au réveil peuvent être traités par thrombolyse en toute sécurité lorsque le traitement est basé sur une fenêtre d'intégrité tissulaire définie par la tomodensitométrie sans contraste et l'angiographie par tomodensitométrie/l'échographie Doppler transcrânienne.

Can J Neurol Sci. 2013; 40: 17-20

Current thrombolytic therapy is limited by the number of patients who arrive both in time for therapy and with a known time of onset. In the Registry of the Canadian Stroke Network, $15 \%$ of ischemic stroke patients awoke with their deficits and these patients had poorer outcomes than those with stroke-whileawake. ${ }^{1}$ Such patients are routinely excluded from thrombolytic consideration on the basis of time. However, recent work with brain imaging (both multimodal magnetic resonance (MR) and computed tomography (CT)) has shown that salvageable brain tissue, the penumbra, exists well beyond a three hour window and among patients with stroke-on-awakening. ${ }^{2}$ Both the DIAS and DEDAS trials have shown that a multimodal MRI paradigm can be used to safely treat patients with thrombolytic therapy out to nine hours from stroke onset. ${ }^{3,4}$ Therefore, time is a surrogate for the patient-specific pathophysiology.

From the Calgary Stroke Program, Department of Clinical Neurosciences, Hotchkiss Brain Institute, University of Calgary, Calgary, Alberta, Canada.

Received June 4, 2012. Final Revisions Submitted August 27, 2012

Correspondence to: Michael D. Hill, Calgary Stroke Program, Department of Clinical Neurosciences, University of Calgary, Foothills Hospital, Rm 1242A, 1403 29th Street NW, Calgary, Alberta, T2N 2T9, Canada.Email: michael.hill@ucalgary.ca. 
However, MRI is globally limited by access and patient compatibility. ${ }^{5}$ Computed tomogram perfusion is probably less limited by patient factors but radiation dose and contrast load are important considerations in deciding on acute perfusion imaging. We have previously shown that patients treated with intraarterial thrombolysis, an average of slightly more than five hours from onset, only benefited from therapy when the baseline noncontrast CT (NCCT) scan showed minimal or no damage as shown by an ASPECTS score $>7 .^{6,7}$ This same relationship cannot be shown for the under-3-hour time window with IV thrombolysis. ${ }^{8}$ However, it is clear that out to six hours from symptom onset, significant areas of early ischemic change (ASPECTS < 4) are associated with a much greater risk of PH2 hemorrhage and death. ${ }^{9}$

We hypothesized that patients with a favorable baseline NCCT scan defined by an ASPECTS $>5$, an intracranial arterial occlusion defined by transcranial doppler ultrasound (TCD) or CT angiogram and disabling stroke symptoms were candidates for thrombolytic therapy. We tested the safety of our hypothesis among patients who awoke with stroke symptoms.

\section{MethodS}

The study was approved by the Calgary Health Region Ethics Board. All patients or their surrogate provided informed consent. The study was conducted at a single centre over 2.5 years (20062009). We educated our Emergency Department triage staff to alert the stroke team for any patient who awoke with a stroke deficit. Patients were screened by the stroke fellow or stroke physician on-call.

Inclusion criteria were a last known well time within 12 hours of emergency department (ED) arrival, stroke-on-awakening, a disabling stroke, a demonstrated extra- or intracranial arterial occlusion (as the cause of stroke symptoms) on CT angiography or TCD (defined by the TIBI criteria). ${ }^{10}$ Initially, the NCCT had to show an ASPECTS score $>7$; half-way through the study we relaxed this criterion to ASPECTS $>5$ and included patients who simply had an undefined time of onset (but still within 12 hours) to improve recruitment. NCCT scans had to be scored by the attending physician and by a second expert reader (neuroradiologist OR stroke neurologist) who did not know the case to ensure that the patient met ASPECTS criteria. Patients with obvious hypodensity, defined as grey matter hypodensity with qualitative lower attenuation than normal appearing white matter, were excluded, even if the ASPECTS score was greater than 5. Transcranial doppler ultrasound studies were conducted by the stroke fellow or staff. The CT angiograms are performed routinely as part of the standard stroke imaging assessment. We diagnosed an arterial occlusion by assessing both the CTA source images and thick slab axial and coronal reconstructed images for an intraluminal filling defect. All patients had to be treated within 60 minutes of the CT scan.

Patients were excluded if they had any of the standard thrombolytic contraindications defined by the NINDS tPA Stroke Trial. ${ }^{11}$ All patients had a follow-up brain CT scan at 24 hours which was interpreted by a neuroradiologist. Clinical outcomes were assessed at 90 days by personnel blinded to the clinical course, certified in the NIH stroke scale score.

Standard descriptive statistics were used to assess the data. All analyses were conducted with STATA (Statacorp, College Station, TX).

\section{RESULTS}

Recruitment was hampered by the lack of direct referral by EMS of patients with stroke-on-awakening. Such patients, according to the local Calgary EMS stroke screen are taken to the nearest hospital rather than bypassed to our stroke centre, because they are beyond the usual thrombolytic window. The change in inclusion criteria by lowering the ASPECTS threshold from ASPECTS $>7$ to ASPECTS $>5$ and including more than just stroke-on-awakening patients allowed us to finish the trial. The justification for lowering the ASPECTS threshold was based upon analysis of the NINDS tPA trial and the ECASS-2 trial where an ASPECTS by treatment interaction was not shown..$^{8,9}$ However, safety concerns were shown with very low ASPECTS scores (ASPECTS < 4). We chose to include patients who suffered strokes while awake but still had an undefined time of onset within the overall 12-hour safety window. A total of five patients were included with an ASPECTS of six or seven and two patients were not stroke-on-awakening cases but instead unwitnessed stroke.

Patient characteristics are described in Table 1. Among 89 screened patients, 20 were successfully treated. Among excluded patients, the primary reasons were: (a) 29 had an ASPECTS $\leq 5$; (b) 19 had well-evolved infarcts on CT; (c) 17 had a mRS > 2; (d) 10 had no demonstrable arterial occlusion or were too clinically mild (ie. not disabled by their stroke) to warrant treatment. Among the 20 treated patients, the number and location of arterial occlusions is described in Table 2 .

Two patients $(10 \%)$ died due to massive carotid territory stroke and two patients $(10 \%)$ died of stroke complications. No patient suffered symptomatic intracranial hemorrhage and there were two patients $(10 \%)$ with asymptomatic ICH (petechial hemorrhage). Good outcome (mRS 0-1) was observed in nine patients $(45 \%)$ [Figure]. Protocol violations occurred in three patients, in whom, on review there was no vessel occlusion on

\section{Table 1: Baseline patient characteristics}

\begin{tabular}{ll}
\hline & $\begin{array}{l}\text { Median (iqr) } \\
\text { or N (\%) }\end{array}$ \\
\hline & $75(35)$ \\
Age & $12(60 \%)$ \\
Gender (male) & $17(85 \%)$ \\
Ethnicity (Caucasian) & $544(881)$ \\
LSW-to-Treatment Time (minutes) & $148(304)$ \\
Awakening-to-Treatment Time & \\
(minutes) & $162(28)$ \\
SBP & $6.5(5.6)$ \\
Glucose (mM) & $8.5(4)$ \\
bASPECTS & $13(19)$ \\
bNIHSS &
\end{tabular}

LSW = last seen well; $\mathrm{SBP}=$ systolic blood pressure; $\mathrm{mM}=$ millimole; bASPECTS = baseline Alberta Stroke Program Early CT score; bNIHSS = baseline National Institutes of Health Stroke Scale score 
Table 2: Vessel status. The occluded vessels were:

\begin{tabular}{ll}
\hline Artery & N \\
\hline & 1 \\
Basilar & 3 \\
Internal Carotid (proximal) & 1 \\
Internal Carotid L-occlusion & 1 \\
Internal Carotid T-occlusion & 2 \\
Internal Carotid stenosis w/ no occlusion & 9 \\
M1-Middle Cerebral & 2 \\
M2-Middle Cerebral & 1 \\
M2-Middle Cerebral + Internal Carotid & \\
\hline
\end{tabular}

CTA was used in 14 patients, TCD in 6.

baseline CT angiography in two. Both of these patients had underlying internal carotid artery (ICA) stenosis. A third patient was treated beyond the 12 hour window after discussion with the medical monitor. All three patients are included in the analysis.

\section{Interpretation}

This study demonstrates that patients with stroke-onawakening or undefined time of onset can be safely treated with intravenous tPA based upon simple NCCT and vascular imaging. We believe that it is possible to simplify the concept of using multimodal MR or CT perfusion imaging to assess penumbra and degree of ischemic brain damage, to select patients for thrombolysis.

The use of a NCCT and CT angiogram or TCD has significant advantages in reducing and simplifying acute stroke imaging. This approach may be successful for a several reasons. First, we know that the region of early hypodensity on CT represents early ischemic edema which is a marker of irreversibly injured brain tissue; ${ }^{12}$ hence, the ASPECTS score estimates the core of ischemia. This observation is confirmed by the linear relationship between CT ASPECTS and the MR diffusion weighted image ASPECTS in major ischemic stroke within six hours of onset. ${ }^{5}$ The high specificity and good sensitivity of noncontrast CT for evaluation of the ischemic brain ${ }^{13,14}$ is widely underappreciated in the stroke community, in part because it takes a careful clinician to assess the baseline CT scan. Second, the degree of ischemic change is clearly correlated with the immediate risk of thrombolysis. ${ }^{15}$ Therefore, the baseline NCCT can both include the diagnosis of ischemic stroke (rather than only excluding hemorrhage) and it can allow us to determine the safety of immediate thrombolysis. Third, advances in TCD and CT angiography have allowed us to make rapid, accurate vascular diagnoses. Finally, the clinical condition of the patient tells us how much and what tissue is not functioning. A large deficit with limited core infarct, as assessed by ASPECTS, implies a perfusion-diffusion mismatch and the potential for tissue salvage with reperfusion. Therefore, in the setting of a vascular occlusion and a favourable NCCT appearance (minimal EIC or high ASPECTS score), the probability that there is salvageable penumbra is high. Such patients are ideal candidates for stroke thrombolysis.

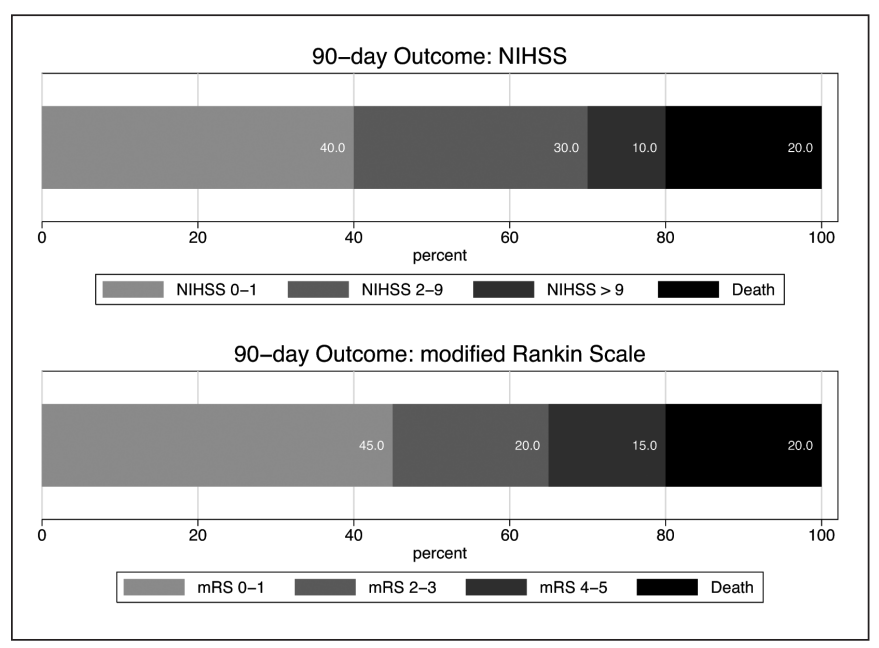

Figure: Outcome at 90 days. $m R S=$ modified Rankin Scale score. NIHSS = National Institutes of Health Stroke Scale score.

Although only $\sim 20 \%$ of the screened patients were eligible for inclusion into our study, the implication is that some patients with stroke-on-awakening suffer their events immediately or just before they wake up, such that their onset-to-treatment time is actually much less than their last-seen-well-to-treatment time. The presence of absence of penumbra is not purely timedependent; other factors such as the collateral circulation and tissue susceptibility to ischemia are also likely relevant.

We chose not to apply intra-arterial therapy primarily in this cohort. While it has pervaded the stroke literature that intraarterial approaches are appropriate for later time windows, it is simply not true that intra-arterial thrombolytic therapy is safer than intravenous therapy. Major adverse events are more common with intra-arterial therapy and our goal was the assessment of safety.

This paradigm is not unique. Indeed, the ingrained concept of "time is brain" is not pathophysiologically valid. ${ }^{16,17}$ This is being increasingly recognized as other studies are now examining the role of imaging in extended time windows, to identify patients for thrombolysis. A reminder of the risk of hemorrhage came with the cessation of the AbESTT-2 study in which the stroke-on-awakening cohort was stopped early for safety reasons (presumedly symptomatic hemorrhage). Two other multicentre studies, the VASTT trial, assessing a new thrombolytic agent (V10153) and the DIAS-2 study (assessing desmoteplase) can include patients with stroke-on-awakening as long as they fit within the overall nine hour window. Other studies are assessing the role of the MRI-defined perfusiondiffusion mismatch paradigm as a patient selection tool with low-dose IV therapy and GP2b3a inhibitors (ROSIE trial) and using the MERCI concentric retriever (MR RESCUE). Two planned randomized trials for patients with stroke on awakening should begin within the next year [WAKE-UP - NCT01525290 and EXTEND - NCT01580839] and provide us with definitive data on the use of the tissue window for patient selection for stroke thrombolysis. 


\section{ACKNOWLEDGEMENTS ANd FUnding}

The study was funded by the Heart \& Stroke Foundation of Alberta/NWT/NU. Drug was provided as in-kind support by Hoffmann-La Roche Canada Ltd.

\section{REFERENCES}

1. Nadeau JO, Fang J, Kapral MK, Silver FL, Hill MD. Outcome after stroke upon awakening. Can J Neurol Sci. 2005;32(2):232-6.

2. Fink JN, Kumar S, Horkan C, et al. The stroke patient who woke up: clinical and radiological features, including diffusion and perfusion MRI. Stroke. 2002;33(4):988-93.

3. Hacke W, Albers G, Al-Rawi Y, et al. The Desmoteplase in Acute Ischemic Stroke Trial (DIAS): a phase II MRI-based 9-hour window acute stroke thrombolysis trial with intravenous desmoteplase. Stroke. 2005;36(1):66-73.

4. Furlan AJ, Eyding D, Albers GW, et al. Dose Escalation of Desmoteplase for Acute Ischemic Stroke (DEDAS): evidence of safety and efficacy 3 to 9 hours after stroke onset. Stroke. 2006; 37(5):1227-31.

5. Barber PA, Hill MD, Eliasziw M, et al. Imaging of the brain in acute ischaemic stroke: comparison of computed tomography and magnetic resonance diffusion-weighted imaging. J Neurol Neurosurg Psychiatry. 2005;76(11):1528-33.

6. Hill MD, Rowley HA, Adler F, et al. Selection of acute ischemic stroke patients for intra-arterial thrombolysis with pro-urokinase by using ASPECTS. Stroke. 2003;34(8):1925-31.

7. Hill MD, Demchuck AM, Tomsick T, Palesch YY, Broderick JP. Using the baseline CT scan to select acute stroke patients for IVIA therapy. AJNR Am J Neuroradiol. 2006;27:1612-16.

8. Demchuk AM, Hill MD, Barber PA, Silver B, Patel SC, Levine SR. Importance of early ischemic computed tomography changes using ASPECTS in NINDS rtPA Stroke Study. Stroke. 2005;36 (10):2110-15.
9. Dzialowski I, Hill MD, Coutts SB, et al. Extent of early ischemic changes on computed tomography (CT) before thrombolysis: prognostic value of the Alberta Stroke Program Early CT Score in ECASS II. Stroke. 2006;37(4):973-8.

10. Demchuk AM, Burgin WS, Christou I, et al. Thrombolysis in brain ischemia (TIBI) transcranial Doppler flow grades predict clinical severity, early recovery, and mortality in patients treated with intravenous tissue plasminogen activator. Stroke. 2001;32 (1):89-93.

11. Tissue plasminogen activator for acute ischemic stroke. The National Institute of Neurological Disorders and Stroke rt-PA Stroke Study Group. N Engl J Med. 1995;333(24):1581-7.

12. Dzialowski I, Weber J, Doerfler A, Forsting M, von Kummer R. Brain tissue water uptake after middle cerebral artery occlusion assessed with CT. J Neuroimaging. 2004;14(1):42-8.

13. von Kummer R, Allen KL, Holle R, et al. Acute stroke: usefulness of early CT findings before thrombolytic therapy. Radiology. 1997;205(2):327-33

14. von Kummer R, Bourquain H, Bastianello S, et al. Early prediction of irreversible brain damage after ischemic stroke at CT. Radiology. 2001;219(1):95-100.

15. Larrue V, von Kummer RR, Muller A, Bluhmki E. Risk factors for severe hemorrhagic transformation in ischemic stroke patients treated with recombinant tissue plasminogen activator: a secondary analysis of the European-Australasian Acute Stroke Study (ECASS II). Stroke. 2001;32(2):438-41.

16. Baron JC, von Kummer R, del Zoppo GJ. Treatment of acute ischemic stroke. Challenging the concept of a rigid and universal time window. Stroke. 1995;26(12):2219-21.

17. von Kummer R. The time concept in ischemic stroke: misleading. Stroke. 2000;31(10):2523-5. 